\title{
KEMAMPUAN BERPIKIR POSITIF DAN EFIKASI DIRI PADA BURUH KULI PANGGUL
}

\author{
Dyah Dharmawanti \\ Fakultas Psikologi \\ Universitas Ahmad Dahlan Yogyakarta \\ dyah1700013200@webmail.uad.ac.id
}

\begin{abstract}
Abstrak
Himpitan ekonomi, dan kemampuan yang tidak memadahi menjadikan rakyat memilih bekerja sebagai kuli panggul. Buruh kuli panggul merupakan pekerjaan yang mengutamakan kekuatan otot badan dan kesabaran ini banyak dijumpai di berbagai pasar tradisonal di Yogyakarta, salah satunya Beringharjo. Subjek penulisan ini adalah lansia berusia 55-80 tahun yang bekrja sebagai kuli panggul di pasar Beringharjo. Tujuan dari penulisan ini adalah memberikan gambaran efikasi diri dan berpikir positif pada buruh kuli panggul. Hasilnya adalah buruh memandang segalanya berdasarkan sisi positif dan menjadikan kinerja dirinya positif juga. Buruh kuli panggul seakan tidak mengenal rasa lelah ketika bekerja dari pagi buta hingga sore hari ini membuktikan efikasi kerja yang baik.
\end{abstract}

Kata Kunci : berpikir positif, efikasi diri, kuli panggul

\section{PENDAHULUAN}

Komunitas adalah sekelompok orang yang saling peduli satu sama lain lebih dari yang seharusnya, saat dalam sebuah komunitas terjadi relasi pribadi yang erat antar para anggota komunitas tersebut karena adanya kesamaan interest atau values (Hermawan, 2008). Sedangkan istilah komunitas dapat di terjemahkan sebagai masyarakat setempat, istilah mana merujuk pada warga-warga sebuah desa, sebuah kota, suku atau suatu bangsa (Soekanto, 2005). Sehingga inti dari kata komunitas adalah sekumpulan orang yang membentuk suatu kelompok yang memiliki berbagai macam latar belakang namun memiliki satu tujuan yang sama. Kelompok komunitas akan berpikir cara memajukan atau meningkatkan kualitas kerja anggota didalamnya dengan senantiasa berpikir rasional dan positif, jika hal tersebut tidak berjalan dengan baik maka komunitas tersebut akan terpecah belah sehingga tidak terjadi keharmonisan dalam bekerja. Komunitas buruh kuli panggul pasar Beringharjo sudah ada sejak zaman dahulu sebelum kemerdekaan Indonesia dimulai. pekerjaan ini mengandalkan kekuatan 
otot seluruh badan dan ditekuni oleh laki-laki maupun perempuan yang sudah lanjut usia (lansia), namun di dominasi oleh kaum perempuan. Buruh kuli panggul berasal dari berbagai daerah di Jawa Tengah seperti Magelang, Klaten, Sleman, Gunung Kidul, Bantul, Kulon Progo, Purworejo, dan Jogja.

James Allan mengatakan bahwa dengan berpikir positif seseorang bisa menentukan pilihannya (Elfiky, 2009). Adanya pikiran-pikiran positif komunitas kuli panggul pasar Beringharjo semakin menambah keyakinan bahwa komunitas kuli panggul memandang semua dari sisi positif baik berawal dari dalam dirinya, orang lain, maupun lingkungannya. Sehingga hal yang terjadi adalah tidak mudah menyerah dan putus asa begitu saja pada keadaan yang dijalaninya. Dengan begitu, individu bisa memilih yang cocok dengan dirinya dan bertanggung jawab atas pilihannya. Penelitian menentukan bahwa dengan memusatkan perhatian pada posisi positif dari suatu keadaan yang sedang dihadapi akan membuat sesorang menjadi lebih mampu mempertahankan emosi positifnya dan mencegah emosi negatif serta membantu dalam menghadapai situasi yang mengancam dan menimbulkan stres (Cridder, dkk, 1983). Seperti permasalahan yang dihadapi oleh kuli panggul, kuli panggul berusaha mencari cara untuk dapat memenuhi kebutuhan hidupnya, meskipun harus bekerja keras 2x lipat ketimbang orang lain. Berpikir positif membuat buruh kuli panggul menjadi lebih tenang dalam bekerja dan tetap saling mengutamakan solidaritas kebersamaan kelompok serta tak lupa untuk tetap saling bergotong-royong. Fordyce (dalam Seligman, dkk, 2005) kondisi psikologis yang positif pada diri individu dapat meningkatkan kemampuan untuk menyelesaikan beragam masalah dan tugas.

Fakta dilapangan menunjukkan bahwa pekerja kuli panggul masih kurang diperhatikan oleh pemerintah. Jika kuli panggul diperhatikan oleh pemerintah, maka kuli panggul dapat bekerja dan mendapatkan kehidupan yang lebih layak karena usia kuli panggul yang sudah renta. Salah satu cara yang dapat dilakukan untuk menumbuhkan pikiran positif adalah membutuhkan dukungan dari orang-orang sekitarnya. Dukungan penting dalam rangka membangkitkan motivasi agar tetap bersemangat memperjuangkan prestasi, meski dirinya cacat fisik (Tentama, 2012). Hal yang ditimbulkan oleh peristiwa ini adalah meningkatnya efikasi diri atau self efficacy. Self efficacy adalah keyakinan seseorang dalam kemampuannya untuk melakukan suatu bentuk kontrol terhadap fungsi orang itu sendiri dan kejadian dalam lingkungan (Feist 
\& Feist, 2006). Efikasi diri menjadi bentuk menyerupai motivasi dalam masing-masing individu buruh kuli panggul untuk selalu yakin bahwa individu kuli panggul dapat melakukan pekerjaan dengan baik dan tidak mengecewakan salah satu pihak meskipun jika dilihat dari usianya sudah tidak mendukung untuk melakukan pekerjaan berat seperti itu. Bandura mengemukakakn beberapa dimensi dari efikasi diri, yaitu magnitude, generality, dan strength. Magnitude, berkaitan dengan tingkat kesulitan suatu tugas yang dilakukan. Generality, berkaitann dengan bidang tugas, seberapa luas individu mempunyai keyakinan dalam melaksanakan tugas-tugas. Strength, berkaitan dengan kuat lemahnya keyakinan seorang individu (Bandura, 1977).

Berdasarkan kajian teoretis yang telah disajikan diatas, maka permasalahan yang diangkat dalam penelitian ini adalah "Hubungan berpikir positif dengan efikasi diri oleh komunitas kuli panggul pasar Beringharjo". Tujuannya melihat secara empiris kemampuan berpikir positif guna meningkatkan efikasi diri oleh buruh kuli panggul. Artinya, semakin tinggi sikap dan tingkat berpikir positif buruh kuli panggul semakin tinggi pula efikasi diri yang dihasilkan dalam kerja yang dilakukan oleh buruh kuli panggul guna pemenuhan kebutuhan dasarnya.

\section{PEMBAHASAN}

Penelitian yang di lakukan dengan pengamatan terhadap subjek dan melihat kesehariannya dalam bekerja serta melakukan wawancara terhadap salah satu narasumber. Ibu Sumisih berusia 63 tahun, beralamat di Sewon, Bantul, Yogyakarta yang bekerja sebagai kuli panggul Pasar Beringharjo. Beliau bekerja sudah selama 30 tahun. Sebelum bekerja sebagai kuli panggul di pasar Beringharjo, sempat bekerja ke Kalimantan dan Semarang sebagai pembantu rumah tangga. Selama 2x pernikahannya ia di karuniahi 1 anak namun sudah tiada dan suami yang kedua sudah sangat tua dan renta.

Jumlah Kuli Panggul

\begin{tabular}{|c|c|c|}
\hline Nama Pasar & Jumlah Buruh Gendong & Pendamping \\
\hline Beringharjo & 200 & Yayasan Yasanti \\
\hline Giwangan & 135 & Yayasan Yasanti \\
\hline Kranggan & 12 & Yayasan Yasanti \\
\hline
\end{tabular}

Sumber: Dinas Pengelola Pasar Kota Yogyakarta, 2015 
Selama pengamatan yang dilakukan di pasar Beringharjo, banyak sekali kuli panggul yang tinggal sementara di sekitaran pasar, baik itu di pinggiran atau emperan pasar atau kios-kios. Di sebelah timur pasar terdapat kurang lebih 70 kuli panggul terdiri dari perempuan dan laki-laki lanjut usia yang setiap hari setelah magrib beristirahat disana menggunakan alas kardus dan karung serta tidur secara berdempetan. Kemudian di selatan pasar juga terdapat hal yang sama dengan jumlah yang kurang lebih 60 kuli panggul di dominasi oleh perempuan, serta kuli panggul yang menyendiri juga terdapat disekitar pinggiran pasar Beringharjo. Hal yang di khawatirkan ketika buruh kuli panggul sedang beristirahat adalah saat hujan tiba karena beristirahat di emperan otomatis akan mudah terguyur oleh air hujan, namun individu tidak mempermasalahkan hal tersebut. Buruh kuli panggul tak jarang juga membawa anak atau cucunya bekerja sebagai kuli panggul. Terkadang saat menjelang magrib ada dermawan mengantarkan nasi bungkus dan minuman untuk buruh kuli panggul.

Berdasarkan perbincangan dengan narasumber diperoleh data buruh kuli panggul di pasar Beringharjo mulai bekerja ketika pukul 04.00 WIB-16.00 WIB dan pada saat pukul 17.00 WIB kuli panggul mulai bersiap untuk bersih-bersih diri seperti mandi karena setelah azan magrib buruh mulai beristirahat. Kuli panggul datang ke pasar Beringharjo tak hanya sekedar membawa badan namun terkadang juga barang dagangan dan pakaian ganti yang disimpan di dalam karung. Biasanya buruh akan pulang ke rumah masing-masing setiap satu minggu sekali atau dua minggu sekali bahkan sebulan sekali untuk menemui keluarga dan menyerahkan uang hasil bekerja. Barang-barang yang di panggul saat bekerja biasanya bahan bahan makanan mentah dan setengah jadi seperti kebutuhan pokok, hingga kerajinan atau tekstil. Buruh kuli panggul bekerja biasanya menggendong barang untuk dibawa dari lantai satu ke lantai dua bahkan tiga atau sebaliknya. Pendapatan rata-rata yang diperoleh oleh kuli panggul berkisar dari Rp.20.000,00-Rp.30.000,00 pada hari biasa namun jika sedang ramai bisa mencapai Rp.50.000,00-Rp.100.000,00.

Penyebab dari banyaknya orang yang bekerja menjadi buruh kuli panggul pasar ialah:

1. Pendidikan yang masih rendah di kalangan masyarakat desa, sehingga ketika bekerja hanya mendapat kesempatan kerja seadanya saja. 
2. Kurangnya kemampuan atau kecakapan di bidang lain, sehingga menjadikan buruh kuli panggul tidak mampu bekerja di bidang profesi lain yang lebih layak.

3. Adanya ajakan dari lingkungan sekitar hingga terjalin sebuah relasi.

4. Himpitan ekonomi yang harus tetap tercukupi, besarnya biaya hidup dimasa sekarang menuntut buruh kuli panggul melakukan hal apa saja agar kebutuhan tetap dapat terpenuhi.

5. Kurangnya lapangan pekerjaan yang sesuai dengan usia para buruh kuli panggul serta kurangnya perhatian dari pemerintah guna mengentaskan masalah tersebut.

Sehingga dampak yang di timbulkan adanya hal tersebut adalah semakin meningkatnya buruh kuli panggul di pasar-pasar tradisional di kota Jogja.

Solusi yang dapat digalakkan guna mengatasi maraknya kuli panggul adalah dengan:

1. Membuka lapangan pekerjaan lebih meluas dan merata serta mempertimbangkan usia pekerja.

2. Memberi pelatihan terhadap buruh kuli panggul seperti berwirausaha.

3. Memberi modal agar buruh kuli panggul dapar berwirausaha dari kecil-kecilan hingga menengah.

4. Menggalakkan program pengentasan kemiskinan secara dini.

5. Memantau perkembangan buruh kuli panggul setelah mendapatkan pelatihan dan pembekalan.

Victor Hugo menyatakan bahwa pikiran adalah kekuatan yang sangat efektif. Tanpanya, setiap kekuatan hanya besar saja (Elfiky, 2009). Berpikir positif juga membuat individu mampu bertahan dalam situasi yang rawan distres (Kivimaki, dkk, 2005). Berpikir positif sangan penting bagi individu, individu yang mampu berpikir positif dapat merasa tenang, rileks, dan dapat menyesuaikan dirinya untuk mengatasi masalah yang dihadapi (Tentama, 2014). Kemampuan berpikir positif guna meningkatkan efikasi diri atau self efficacy ditunjukkan oleh Ibu Sumisih dan rekanrekan kerjanya dengan bentuk bekerja dengan giat tanpa mengenal rasa lelah. Bekerja sebagai kuli panggul pasar bukanlah hal yang mudah dan bisa dijalani oleh setiap orang. Para buruh yang berasal dari berbagai daerah di Jawa Tengah pergi bekerja dengan penuh beban. Para buruh kuli panggul bekerja jauh dari keluarga dan harus tetap bekerja selama \pm 12 jam. Rata-rata keadaan keluarga para buruh kuli panggul ialah orang yang 
kurang mampu atau menengah kebawah. Sehingga kebutuhan dan himpitan ekonomi yang semakin melonjak harus tetap dipenuhi secara berkala. Buruh kuli panggul secara bersama-sama berpikir positif tentang rencana yang harus dikerjakan guna memenuhi kebutuhan keluarga. Ibu Sumisih dengan rekan-rekan kerjanya, bekerja dengan rasa kekeluargaan, hal ini dilihat dari cara dari buruh kuli panggul bekerja saat terdapat pembagian kerja yang adil sehingga tidak terjadi perebutan atau pengambilan hak orang lain. Menurut Marpaung (2009) cara pandang yang positif akan memampukan individu untuk selalu optimis memandang situasi dan kondisi yang sedang terjadi di tengah lingkungannya. Para kuli memiliki tekad yang kuat agar dapat memenuhi kebutuhan hidup keluarga, seperti Ibu Sumisih yang rela bekerja seorang diri guna menghidupi dirinya dan suaminya yang sudah renta. Sejak lama Ibu Sumisih bekerja secara mandiri tanpa merepotkan orang lain itu artinya dirinya dapat memecahkan persoalannya sendiri.

Berpikir positif juga membantu seseorang dalam memberikan sugesti positif pada diri saat menghadapi kegagaglan, saat berperilaku tertentu, dan membangkitkan motivasi (Hill \& Ritt, 2004). Berpikir positif juga berperan dalam penerimaan diri pada individu, semakin mampu individu berpikir positif terhadap suatu keadaannya, maka semakin tinggi pula penerimaan diri pada individu (Tentama, 2010). Kemampuan berpikir positif guna meningkatkan efikasi kerja juga di tunjukkan oleh kuli panggul pasar Beringharjo yaitu melalui bekerja sebagai kuli panggul dengan upah yang tidak seberapa menjadikan buruh kuli panggul dapat memiliki pribadi yang mandiri. Pribadi yang mandiri dan terbentuk pribadi yang menerima. Kemudian terbentuk hubungan intim antara Ibu Sumisih dengan rekan-rekan kuli panggul lainnya, buruh kuli panggul telah menganggap sesama rekannya sebagai keluarga yang harus saling melindungi satu sama lainnya. Hubungan yang benar-benar terjadi antara berpikir positif dan efikasi diri adalah kuli panggul menjadi orang yang rajin dan tekun dalam bekerja, rela terbangun lebih awal daripada orang lain dan bekerja lebih lama dibanding orang lain. Semakin kuat pikiran positif buruh kuli panggul tentang bekerja setiap hari tanpa mengeluh, semakin ringan beban yang akan dipikul. Itu artinya semakin mudah dalam memenuhi kebutuhan, maka menjadikan tuntutan ekonomi semakin berkurang sehingga buruh kuli panggul tidak akan terbebani terus-menrus. Berpikir positif adalah cara memandang segala persoalan yang muncul dari sudut pandang yang positif, karena dengan berpikir 
positif individu mempunyai pandangan bahwa setiap permasalahan pasti ada jalan pemecahannya dan suatu pemecahan yang tepat diperoleh melalui proses intelektual yang sehat (Peale, 2009).

Semakin giat buruh kuli panggul bekerja, menjadikan buruh kuli panggul menjadi orang yang sederhana dan tidak memamerkan harta kekayaan yang telah diperolehnya selama ini. Semakin seseorang berpikir positif maka orang tersebut akan jauh terhindar dari depresi dan pesimis. Serta manfaat dari berpikir positif yang dilakukan oleh kuli panggul selain meningkatkan efikasi kerja ialah meningkatkan produktifitas tubuh. Sehingga tubuh tetap sehat dan terhindar dari penyakit lupa, oleh karenanya dapat bekerja tanpa ada beban yang berarti. Berpikir positif, selain efikasi kerja yang dihasilkan, sikap menjadi lebih tenang. Adanya kemampuan berpikir positif, modal yang dimiliki menjadi penunjang kuli panggul yang baik.

Hasil analisis yang dilakukan menyatakan bahwa adanya hubungan antara kemampuan berpikir positif yang amat besar oleh buruh kuli panggul pasar Beringharjo guna meningkatkan efikasi diri dalam bekerja dilapangan. Buruh kuli panggul memiliki kemampuan berpikir positif dan efikasi diri yang baik, hal ini dibuktikan saat buruh kuli panggul dapat bertahan dengan caranya sendiri dan terlihat saat bekerja dilapangan, seperti halnya dengan Ibu Sumisih. Himpitan ekonomi yang melanda buruh kuli panggul menjadikan pribadinya yang pantang menyerah dan rela bekerja demi pemenuhan kebutuhan keluarga. Kiprah seorang wanita dalam bekerja mengidentifikasikan bahwa wanita sanggup membantu memenuhi dalam mencari nafkah untuk keluarga serta adanya kebutuhan yang harus segera dipenuhi. Serta semangat yang tinggi menjadikan buruh kuli panggul semakin giat bekerja hari demi hari.

\section{KESIMPULAN}

Buruh kuli panggul Pasar Beringharjo sudah ada sejak zaman dahulu sebelum kemerdekaan Indonesia dimulai. Buruh kuli panggul berasal dari berbagai daerah di Jawa Tengah seperti Magelang, Klaten, Sleman, Gunung Kidul, Bantul, Kulon Progo, Purworejo, dan Jogja kota. Banyak faktor yang mempengaruhi masyarakat memilih pekerjaan sebgaai buruh kuli panggul. Pekerjaan yang ditekuni oleh lansia ini mengandalkan kekuatan otot seluruh badan. Adanya kemampuan berpikir positif buruh 
kuli pangggul guna meningkatkan efikasi diri dalam bekerja adalah salah satu kemampuan luar biasa, karena dengan hal tersebut membuktikan adanya semangat buruh kuli panggul dalam bekerja guna memenuhi kebutuhan sehari hari. Selain itu, berpikir positif juga meningkatkan penerimaan diri dan motivasi diri agar tetap berusaha. Kemampuan berpikir positif menjadikannya tetap tenang dalam bekerja dan terhindar dari stress meskipun sebenarnya buruh kuli panggul memikul beban yang sangat berat, mengingat buruh kuli panggul bekerja jauh dari keluarga. Efikasi diri dalam diri buruh kuli panggul saat bekerja diwujudkan dengan menunjukkan bahwa dirinya sanggup bekerja dari pagi buta hingga sore hari dan selalu menunjukkan prestasi kerja yang bagus dilapangan. 


\section{DAFTAR PUSTAKA}

Bandura, A. (1997). Self Efficacy: The Exercise of Control. New York: W. H. Freeman and Company.

Cridder, A. B., Goothals, G. R., Kavanough, R. D., \& Salmon, P. R. (1983). Ps cholog. New York: Scoot, Foresmen and Company.

Hill, N. \& Ritt, M. J. (2004). Keys to positive thinking. Jakarta: Bhuana Ilmu Populer

Hermawan, K. (2008). Arti komunitas. Jakarta: Gramedia Pustaka Utama.

Kivimaki., dkk. (2005). Optimism and pessimism as predictors of change in health after death or onset of severe illness in family. Journal of Health Psychology, 24(4), 413-421.

Elfiky, I. (2009). Terapi berpikir positif: biarkan mukjizat dalam diri anda melesat agar hidup lebih sukses dan lebih bahagia. Jakarta: Zaman.

Feist, J. \& Feist, G. J. (2006). Theories of personality. Yogyakarta: Pustaka Pelajar

Marpaung, P. (2009). Setengah isi setengah kosong “Half Full-Half Empty”. Bandung: MQS Publishing.

Peale, N.V. (2009). The Power of positive thinking. Yogyakarta: Ragam Media.

Seligman., dkk. (2005). Positive psychology progress: empirical validation of interventions. Journal of American Psychologist. 60(5), 410-421.

Tentama, F. (2010). Berpikir positif dan penerimaan diri pada remaja penyandang cacat tubuh akibat kecelakaan. Humanitas VII(1), 66-75.

Tentama, F. (2012). Membangkitkan pikiran positif difabel. Republika, 76.

Tentama, F. (2014) Hubungan positive thinking dengan self-acceptance pada difabel (bawaan lahir) di SLB negeri 3 Yogyakarta. Jurnal psikologi integratif, 2(2), 17 